\title{
Ophthalmological Status of School Children with Dyslexia
}

\author{
HENRY AASVED
}

Bergen, Norway

It is a great honour for me to be the European Guest Lecturer at the Oxford Ophthalmological Congress.

For the past few years I have undertaken an extensive analysis of the ocular status of school children. This project was originally a large educational and psychological investigation of school children in Bergen coordinated by Professor H. J. Gjessing at the University of Bergen. We were, in our Eye Department, fortunate in being able to perform eye examinations on the same children.

From the ophthalmological point of view there have been, and still are, many controversial ocular phenomena related to reading difficulties. Impaired vision may, of course, cause reading problems. It is common, however, that when people with limited sight manage to read, with or without visual aids, this is done in a normal fashion, although for some this is somewhat slower than for those with normal vision. Reading disturbances may also occur when there is an insufficiency of convergence and in relatively few cases in those with ordinary latent strabismus. Other controversial points are refractive errors, saccadic eye movements, impaired fusion, visual suppression and factors concerning eye and brain dominance, especially crossed dominance. During the past few years there has been interest in the phenomena of the reference eye, (the dominant or leading eye in a binocular situation). Some optometrists have shown a great interest in the field of dyslexia with special reference to treatment with prismatic glasses. ${ }^{1-38}$
From the neurological point of view there are also some phenomena under consideration i.e. minimal brain dysfunction, electrophysiological brain changes and anatomical brain changes shown by computer tomography. ${ }^{39-47}$

Different professions approach reading problems from different angles. With this in mind, it was of great interest to carry out a series of eye examinations in the Bergen study. One cohort from the Bergen schools, 3217 pupils, was the subject of very extensive analysis from the educational and psychological points of view. This was done during the first and second grades with a follow up at the third and fourth grades. At the end of first grade examinations were carried out by orthoptists and ophthalmic assistants on about 3,000 pupils, ( $90 \%$ of the whole group). Thus we obtained considerable data from two different professions on the same school children and extensive analysis has been done to correlate the relationships between the eye characteristics and the reading and orthographic writing ability.

The screening examinations gave much epidemiological data, but Table I shows only the occurrence of squint. The sum of manifest and intermittent strabismus was about $4 \%$ on examination both for reading and at a distance of 6 metres.

For near distance latent strabismus occurred in about $80 \%$ of cases. Thus, at near distance, latent strabismus is a normal finding. At a distance of 6 metres heterophoria was found in slightly less than $50 \%$ of those examined. 
Table I Phoria/tropia among the school children

\begin{tabular}{lrrrrr}
\hline & \multicolumn{4}{c}{ Fixation distance } \\
& \multicolumn{2}{c}{$0.3 \mathrm{~m}$} & \multicolumn{3}{c}{$6 \mathrm{~m}$} \\
Phoria/tropia & No. & $\%$ & No. & $\%$ \\
\hline Manifest strabismus & 82 & 2.7 & 93 & 3.1 \\
Intermittent strabismus & 41 & 1.4 & 25 & 0.9 \\
Latent strabismus & 2435 & 81.2 & 1376 & 46.3 \\
Orthophoria & 440 & 14.7 & 1477 & 49.7 \\
\hline Total no. examined & 2998 & 100.0 & 2971 & 100.0 \\
\hline
\end{tabular}

Figure 1 shows different visual acuity combinations versus reading ability. Although the best visual acuity combination shows the best curve with the lowest figure at the poorest reading level and the highest figure among the best readers, the rest of the visual acuity combinations shows an almost similar course, and the differences were not statistically significant.

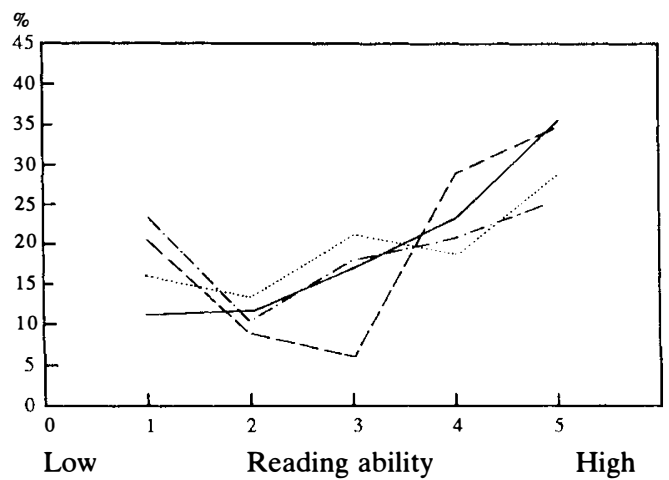

Visual acuity combinations:

$$
\begin{array}{ll}
\$ 5 / 7,5-\$ 5 / 7,5 \ldots & \$ 5 / 7,5-5 / 10--- \\
>5 / 7,5-\leqslant 5 / 15 \cdots \cdots \cdots & \leqslant 5 / 10-\leqslant 5 / 10-\cdot \cdot \cdot-
\end{array}
$$

Fig. 1. Visual acuity versus reading ability.

The curves for the children with latent, intermittent and manifest strabismus compare well with the curve for scholars with orthophoria (Fig. 2). Analysis of the different types of latent strabismus showed closely related curves, where the best curve is represented by scholars with some vertical component in their strabismus (Fig. 3).

The curves for children with crossed and uncrossed eye and brain dominance lie close to each other and to the curve for the total

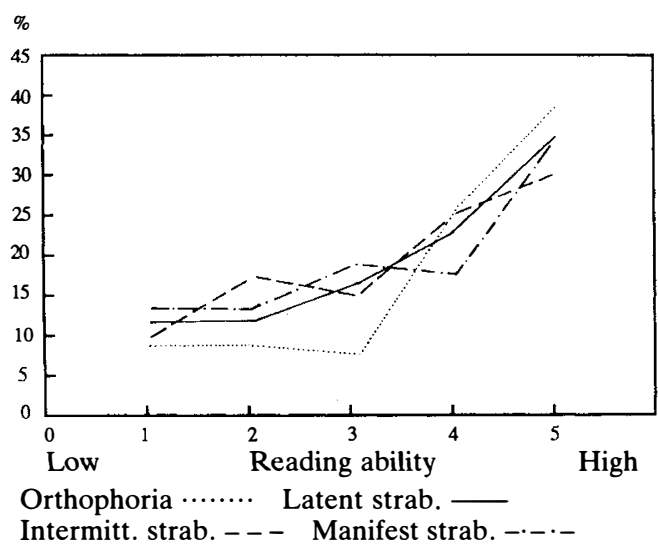

Fig. 2. Phoria/Tropia $0.3 \mathrm{M}$ versus reading ability.

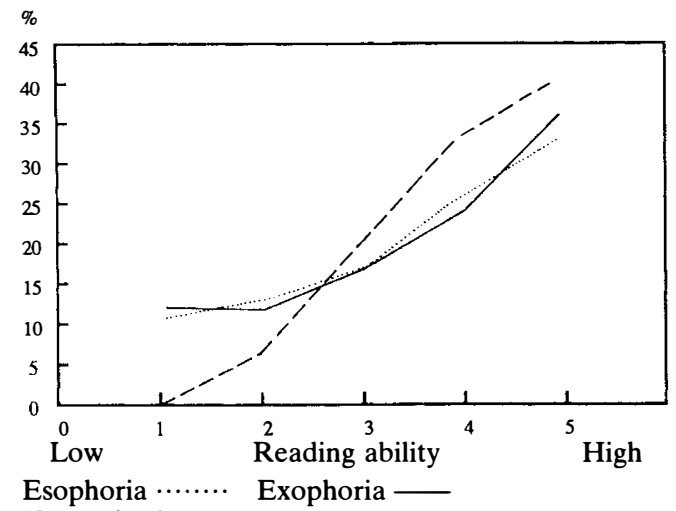

Hyperphoria - - -

Fig. 3. Latent strabismus $0.3 \mathrm{M}$ versus reading ability.

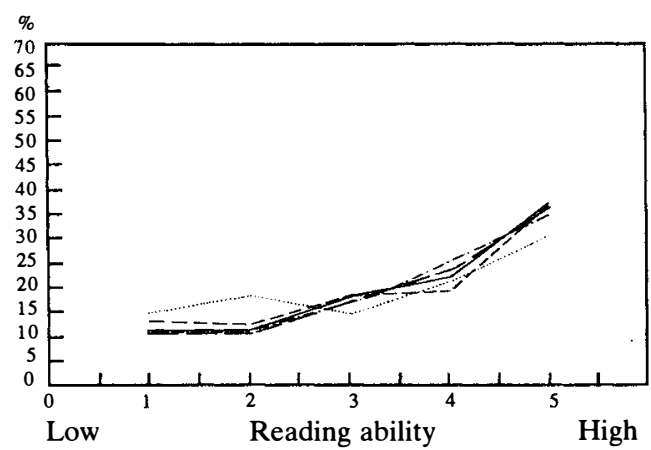

Dominance Eye Hand:

$$
\begin{aligned}
& \text { Right-Right } . . . . . \\
& \text { Right-Left }-\cdot-\cdot \text { Left-Left }--- \\
& \text { Total material }-
\end{aligned}
$$

Fig. 4. Crossed and uncrossed dominance versus reading ability.

number tested (Fig.4). The curves for the different prism fusion findings show almost the same course (Fig. 5). . 


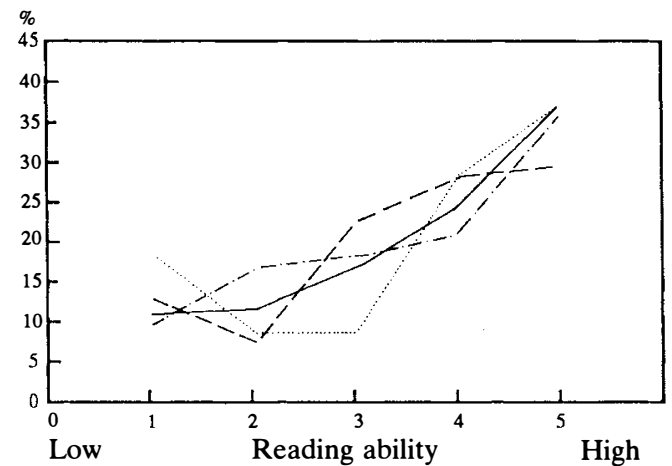

Prism fusion:

$$
\begin{aligned}
& >20 \mathrm{D}- \\
& \text { None }-\cdot-\cdot-
\end{aligned}
$$

Fig. 5. Prism fusion versus reading ability.

In performing the analysis we also took into account different factors which might influence the relationship between eye characteristics and reading ability. A very important point in this context is the differentiation of the children's school ability. Based on psycho- logical analysis the children were divided into four school ability groups, with the dividing points at minus 1 , zero and plus 1 standard deviation. When comparing the groups of school children with the lowest and highest achievement rate we obtained the course of curves for the eye characteristics as shown in Figure 6, which represents visual acuity versus reading ability. In the group with the lowest ability the highest figures were found among the poorest readers, and the lowest figures amongst the best readers, while the curves for children in the higher achievement group showed almost the reverse, with lowest figures among the poorest readers and most of the pupils in the best reader group. The results were independent of the visual acuity. It is therefore very important to take into consideration many factors when talking about the relationship between all kinds of eye functions and reading ability.

Table II gives a summary of some of the eye characteristics found in children at different

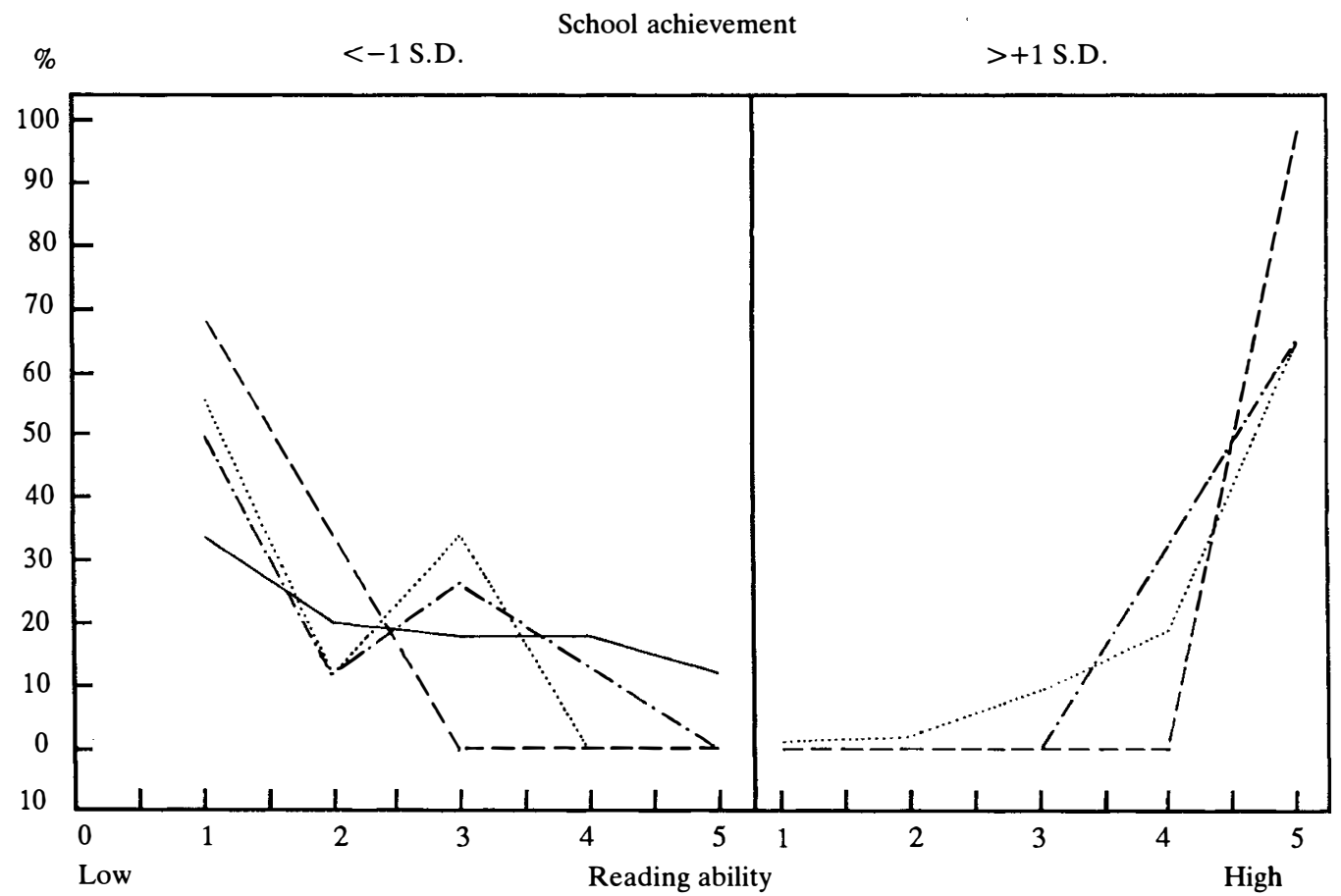

Visual acuity combinations:

$\$ 5 / 7,5->5 / 7,5 \longrightarrow>5 / 7,5-5 / 10---\$ 5 / 7,5-\leqslant 5 / 15 \cdots \cdots \cdots \leqslant 5 / 10-\leqslant 5 / 10-\cdot-\cdot-$

Fig. 6. Visual acuity versus reading ability and school achievement. 
Table II Ocular characteristics at various reading ability levels

\begin{tabular}{lcccccc}
\hline $\begin{array}{l}\text { Reading } \\
\text { Level }\end{array}$ & $\begin{array}{c}\text { Stereopsis } \\
\text { negative } \\
\%\end{array}$ & $\begin{array}{c}\text { Manifest } \\
\%\end{array}$ & $\begin{array}{c}\text { Strabismus: } 1 / 3 M \\
\text { Intermittent } \\
\%\end{array}$ & $\begin{array}{c}\text { Latent } \\
\%\end{array}$ & $\begin{array}{c}\text { Prism fusion } \\
<20 \\
\%\end{array}$ & $\begin{array}{c}\text { Central } \\
\text { Suppression } \\
\%\end{array}$ \\
\hline 1. & 5.6 & 3.3 & 1.3 & 83.8 & 6.7 & 10.3 \\
2. & 7.3 & 3.2 & 2.3 & 83.2 & 6.5 & 10.1 \\
3. & 8.4 & 3.2 & 1.4 & 79.5 & 7.3 & 8.2 \\
4. & 4.9 & 2.1 & 1.6 & 79.8 & 6.4 & 7.4 \\
5. & 5.3 & 2.7 & 1.3 & 79.4 & 5.7 & 7.9 \\
\hline & 153 & 72 & 39 & 2097 & 165 & 218 \\
$\mathrm{Chi}^{2}, \mathrm{p}$. & .13 & .74 & .80 & .33 & .84 & .45 \\
\hline
\end{tabular}

levels of reading ability. The ocular findings are almost the same through the different reading levels. The conclusion of the analysis on this general basis was that among the pupils with low reading ability there were no ocular characteristics which had a statistically significant difference from those of pupils at the higher reading levels. It should be mentioned, however, that these results represent groups of pupils and one cannot exclude the possibility that there may be a connection between visual problems and reading and writing difficulties for certain individual pupils. The pupils with different types of reading and writing difficulties based on educational and psychological analysis therefore underwent an extensive follow-up examination at the orthoptic department and also by one of the professors in the eye department. The following eye functions were examined:

(i) Visual acuity, refraction by retinoscopy in cycloplegia.

(ii) Eye position by cover test and prism cover test.

(iii) Ocular motility.

(iv) Convergence ability.

(v) Accommodation.

(vi) Simultaneous perception.

(vii) Fusion and stereopsis examined on the synoptophore.

(viii) Prism fusion test.

(ix) Bifoveal fixation examined by the 4 diopter prism base out test.

(x) Examinations of the dominant eye both in the monocular situation and with special interest in 'the reference eye test'.
In addition we obtained information from the parents about the child's reading ability.

The total dyslexia group involved 259 pupils, that is approximately $8 \%$ of the cohort, of whom 162 were boys $(62.5 \%)$ and 97 girls (37.5\%). Among these, 253 participated in the initial eye examination and 204 went through the extensive follow-up examination. With the remaining 49 dyslexia cases, the analyses were made separately on the basis of the eye data from the screening tests.

On the basis of the educational-psychological tests the 259 pupils were divided into 4 main dyslexia types, according to the Gjessing-model: Auditory (99), audiovisual (22), visual dyslexia (71) and others (67). The last group comprises secondary dyslexia types due to exogenous factors such as emotional, educational (school, home), foreign language and other factors.

The dyslexic pupils were divided into 4 school ability groups. On the basis of the achievement tests administered during the first four grades, the pupils were also divided into 3 groups according to their educational progress. The ocular data has been analysed separately for the different sub-groups of dyslexic children in order to avoid factors which may distort the final results. This paper deals with the total groups of dyslexic patients. This is justified because the sub-grouping did not give any further information regarding the relationship between eye characteristics and reading difficulties.

Table III shows the prevalence of some of the most important eye conditions in the various dyslexia types, compared to the normal readers, given in percentages.

The illustrations indicate a tendency 
Table III Prevalence of eye conditions in the various dyslexia types compared to normal readers

\begin{tabular}{|c|c|c|c|c|c|}
\hline Characteristic & $\begin{array}{c}\text { Normal readers } \\
\%\end{array}$ & $\underset{\%}{\text { Auditory }}$ & $\begin{array}{c}\text { Dyslexia types } \\
\text { Audio-visual } \\
\%\end{array}$ & $\begin{array}{l}\text { Visual } \\
\%\end{array}$ & $\begin{array}{c}\text { Others } \\
\%\end{array}$ \\
\hline \multicolumn{6}{|l|}{ Visual acuity $<6 / 9$} \\
\hline in one or both eyes & 4.2 & 5.1 & 9.1 & 2.9 & 4.0 \\
\hline Manifest strabismus $0.33 \mathrm{~m}$ & 3.9 & 7.1 & 9.1 & 4.3 & 7.9 \\
\hline \multicolumn{6}{|l|}{ Latent strabismus $0.33 \mathrm{~m}$} \\
\hline Convergent & 11.1 & 20.2 & 18.2 & 13.0 & 19.0 \\
\hline Divergent & 69.8 & 64.6 & 68.2 & 78.3 & 61.9 \\
\hline Convergence ability $>14 \mathrm{~cm}$ & 3.6 & 3.0 & 4.5 & 4.3 & 1.6 \\
\hline \multicolumn{6}{|l|}{ Simultaneous perception } \\
\hline prism $>20 \mathrm{D} 0.33 \mathrm{~m}$ & 2.3 & 4.0 & 4.5 & 1.4 & 4.8 \\
\hline Prism fusion $<20 \mathrm{D}$ & 6.1 & 6.1 & 9.1 & 2.9 & 6.3 \\
\hline Poor stereopsis & 5.9 & 7.1 & 9.1 & 1.4 & 7.9 \\
\hline Central suppression & 8.3 & 10.1 & 13.6 & 7.2 & 9.5 \\
\hline $\mathbf{N}$ & $\sim 2.740$ & 99 & 22 & 69 & 63 \\
\hline
\end{tabular}

towards somewhat higher prevalances of some eye characteristics in some of the dyslexia types than among normal readers. This refers to limited visual acuity in one or both eyes, manifest strabismus and latent convergent strabismus. These differences, however, are not statistically significant for any of the groups. Most of the eye characteristics occurred with about the same prevalence in the different dyslexia groups as among normal readers. This was found for spherical refraction, astigmatism, exophoria, ocular motility, convergence ability, simultaneous perception, fusion, stereoscopic vision as well as central visual suppression. All the pupils had accommodation to less than $12 \mathrm{~cm}$ from the eyes.

Special attention was paid to the reference eye test. This examination of the dominant or leading eye in a binocular situation is done on the synoptophore. Pictures are used where details stimulate the central two degrees of the retina. The evaluation of the reference eye is not simple, and to get more reliable information the children were sent for again and the test was repeated ten times for each child. The examination was also carried out on a comparable control group of children. The examination can demonstrate the normal reference eye when the leading eye is on the same side as the preferred hand, crossed correspondence when the reference eye and preferred hand are on opposite sides, alternating or shifting correspondence which means that a stable reference eye is not established. The result may also show that a reference eye has not developed at all, as in cases with suppression of central vision in manifest strabismus. The initial research ${ }^{12}$ seemed to indicate that a crossed reference eye occurred with particularly high frequency in cases with visual dyslexia. Later observations seemed to indicate that unstable reference eye occurred particularly in visual dyslexia. ${ }^{19}$ As a consequence of these results great efforts have been made to change or establish a stable reference eye by occlusion. Later investigations, however, have raised doubt about the validity of these observations..$^{6,38,47}$ The results of the reference eye test can be seen in Figs. 7

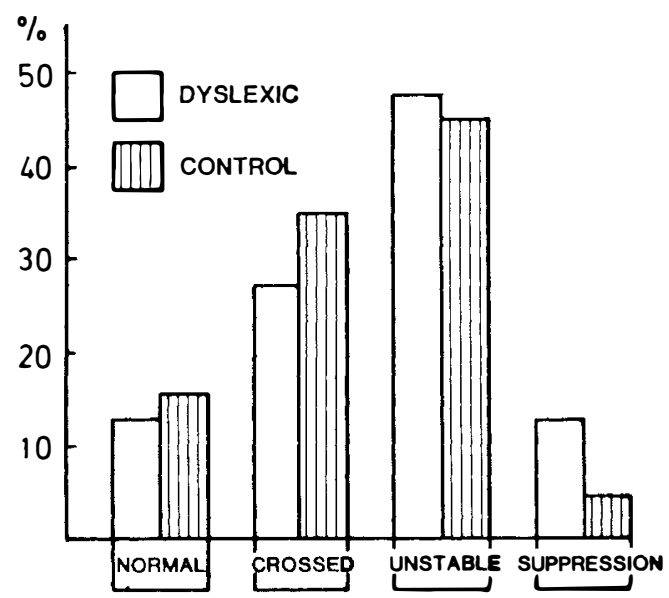

Fig. 7. Reference eye test for 171 dyslexic children and 89 controls. 


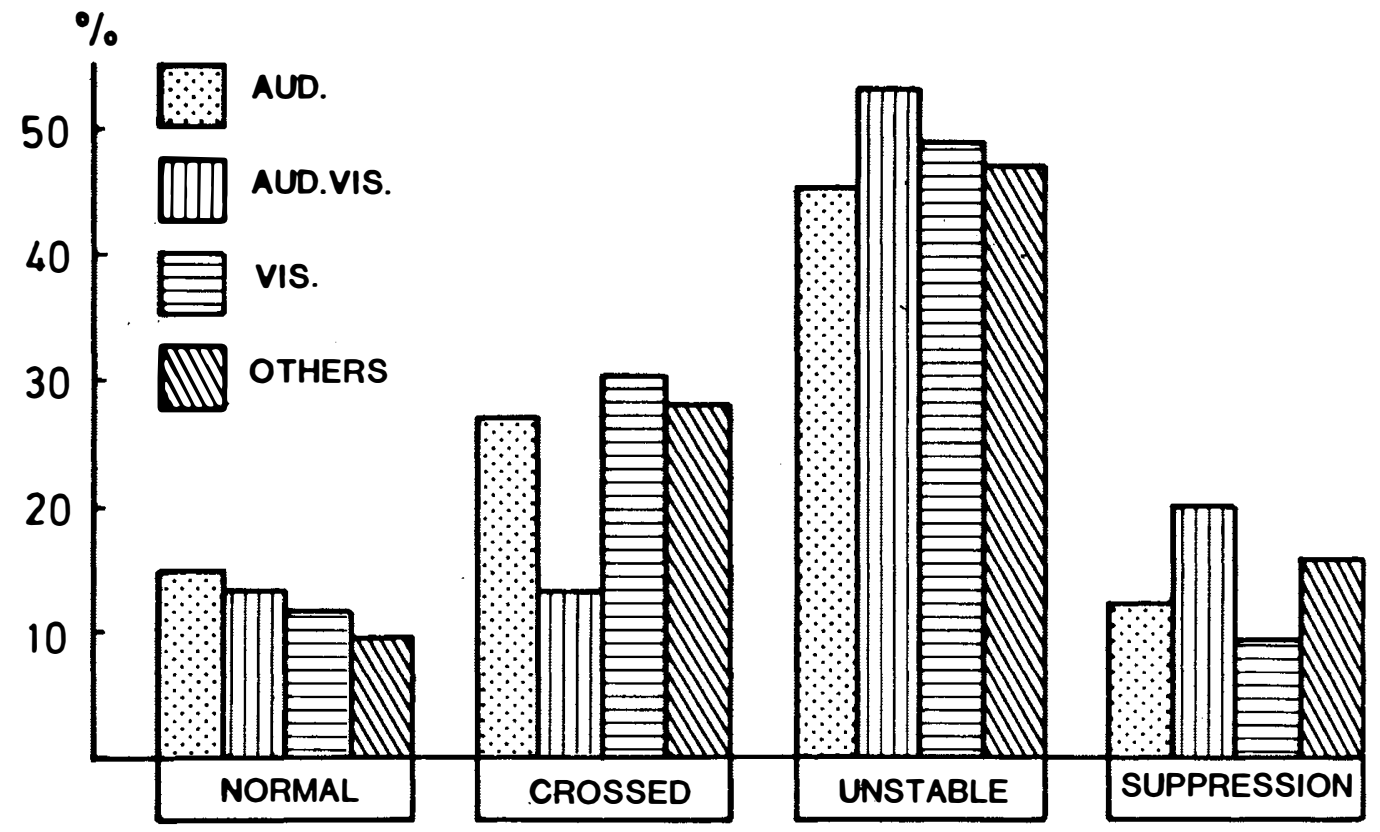

Fig. 8. Reference eye test for 171 dyslexic children by type of dyslexia.

and 8 . When comparing the dyslexia group and the control group the test data are very much the same. Figure 8 also shows that in different dyslexia groups shifting reference eye occurred most frequently, but there were no significant differences between the various dyslexia groups. Thus we have no scientific basis for treatment of any kind of dyslexia by occlusion.

\section{Eye conditions requiring additional examinations}

At the follow-up examination there were 55 pupils whose eye conditions required further examination and evaluation, among these were 26 children with errors of refraction, 15 with manifest strabismus and 16 with latent strabismus. Three children in the last group also had errors of refraction. They were distributed in the four dyslexia groups in approximately the same way as for the total dyslexia group. A follow-up examination of these 55 children 5 years after the screening gave some interesting findings (Table IV). Among the 26 pupils with errors of refraction, 24 had glasses or were prescribed glasses in 1980. Only 8 of these pupils still used the glasses 5 years later, all of them with hyper- metropia of more than 3 dioptres or astigmatism of more than 2 dioptres while the remaining 16 children felt no need for their glasses after a short trial period. When differentiating the pupils according to aptitude level most of the pupils who scored higher than minus 1 standard deviation were good readers, while the pupils with lower school ability were distributed evenly in the 3 categories of reading ability.

The same pattern was also found for the pupils with latent strabismus. In 1980 seven of them were prescribed prismatic glasses, but only two used these glasses 5 years later and the pupils in the lower ability had a clear tendency to be poorer readers than the pupils with higher scores.

Among the pupils with manifest strabismus there was a higher percentage using the prescribed glasses 5 years later, but the distribution in the 3 categories of reading ability showed the same pattern as the 2 other groups of children.

These, in addition to other findings, indicate that dyslexic pupils with high school ability more easily overcome reading difficulties and may benefit more from educational treatment than the pupils with a low aptitude level. 
Table IV. Ocular and reading status among 55 dyslexic children five years after screening

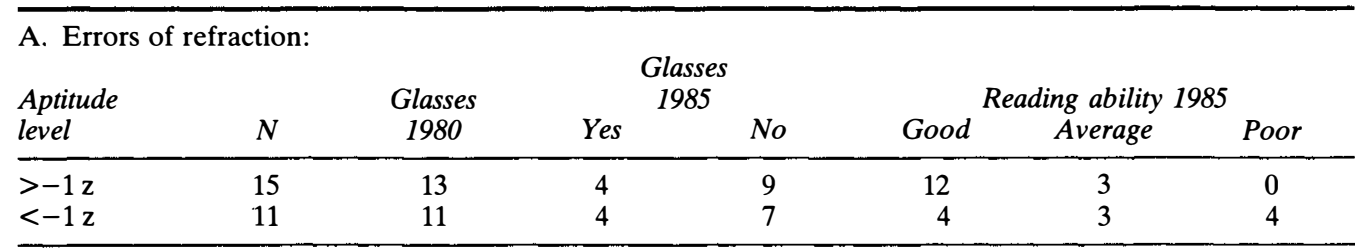

B. Manifest strabismus:

\begin{tabular}{lccccccc}
$\begin{array}{l}\text { Aptitude } \\
\text { level }\end{array}$ & $N$ & Surgery & 1980 & 1985 & Good Reading ability 1985 \\
\hline$>-1 \mathrm{z}$ & 10 & 3 & 5 & 5 & 8 & 2 & 0 \\
\hline$<-1 \mathrm{z}$ & 5 & 1 & 3 & 1 & 2 & 1 & 2 \\
\hline
\end{tabular}

C. Latent strabismus:

\begin{tabular}{|c|c|c|c|c|c|c|c|c|}
\hline \multirow{2}{*}{$\begin{array}{l}\text { Aptitude } \\
\text { level }\end{array}$} & \multirow[b]{2}{*}{$N$} & \multicolumn{2}{|c|}{$\begin{array}{c}\text { Refractive } \\
\text { glasses }\end{array}$} & \multicolumn{2}{|c|}{ Prismatic glasses } & \multicolumn{3}{|c|}{ Reading ability 1985} \\
\hline & & 1980 & 1985 & 1980 & 1985 & Good & Average & Poor \\
\hline$>-1 \mathrm{z}$ & 11 & $2 *$ & 1 & 2 & 1 & 7 & 4 & 0 \\
\hline$<-1 \mathrm{z}$ & 6 & $1^{*}$ & 0 & $5^{* *}$ & 1 & 0 & 2 & 3 \\
\hline
\end{tabular}

* These 3 children are also included in $\mathrm{A}$.

** One pupil had prismatic glasses after surgery.

\section{Conclusion}

To sum up we can draw the following conclusion from the extensive analysis: The ocular status is almost the same among dyslexic children as among children with normal reading ability.

Most children with abnormal eye conditions do not have dyslexia.

In general there is no causal relationship between eye characteristics and reading/writing difficulties.

However, in dyslexic children, eye abnormality may be an additional burden and should be given optimal treatment.

\section{References}

${ }^{1}$ American Academy of Paediatrics, American Academy of Ophthalmology and Otolaryngology, American Association of Ophthalmology. The eye and learning disabilities. J. Learning Disabilities 1973 6: 332-333.

${ }^{2}$ Benton CD jr., McCann JW jr; and Larsen M. Dyslexia and dominance. J. Ped. Ophthalmol. 1965 2: 53-7.

${ }^{3}$ Benton CD jr: The eye and learning disabilities. Comment. J. Learning Disabilities, 1973; 6: 334-6.

${ }^{4}$ Berner CE and Berner DE: Relation of ocular dominance, handedness, and the controlling eye in binocular vision. Arch. Ophthalmol. 1953; 50: 603-8.

${ }^{5}$ Bettman JW jr, Stern EL Whitsell LJ and Gofman
HF: Cerebral dominance in developmental dyslexia. Arch. Ophthalmol. 1967; 78: 722-9.

${ }^{6}$ Bishop DVM, Jancey C, and Steel A McP: Orthoptic status and reading disability. Cortex 1979; 15: 659-66.

${ }^{7}$ Brod N and Hamilton D: Monocular-binocular coordination $v s$. Hand-eye dominance as a factor in reading performance. Am. J. Optom. 1971; 48, 123-9.

${ }^{8}$ Boe OO: The extent of the connection between cerebral dominance of speech functions (auditory and vocal), hand dominance, and dyslexia. J. Educational Research 1972; 16: 61-8.

${ }^{9}$ Delacato $\mathrm{CH}$ : Neurological organisation and reading. Springfield 1966.

${ }^{10}$ Dunlap EA: Role of strabismus in reading problems. Trans. Pennsyl Acad. of Ophthalmol. and Otolaryngol 1965; 18: 9-15.

${ }^{11}$ Dunlop P: Orthoptic management of learning disability. Br. Orthopt. J. 1979; 36: 25-35.

12 Dunlop DP and Dunlop P: New concepts of visual laterality in relation to dyslexia. Austral. J. Ophthalmol, 1974; 101-12.

${ }^{13}$ Dunlop DB and Dunlop P: A new orthoptic technique in learning disability due to visual dyslexia. I 'Orthoptics past, present and future'. Ed. by Moore, S., Mein, J., and Stockbridge, L. Stratton Intercont., New York 1976, 317-23.

${ }^{14}$ Dunlop DB, Dunlop P and Fenelon B: Vision-laterality analysis in children with reading disability: The results of new techniques of examination. Cortex, 1973; 9: 227-36.

${ }^{15}$ Eames TH: Comparison of eye conditions among 1,000 reading failures, 500 ophthalmic patients, 
and 150 unselected children. Am. J. Ophthalmol. 1948; 31: 713-7.

${ }^{16}$ Eames TH: The Influence of hypermetropia and myopia on reading achievement. Am. J. Ophthalmol. 1955; 39: 375-7.

${ }^{17}$ Eames TH: Reading failures and non-failures. Am. J. Ophthalmol. 1959; 47: 74-7.

${ }^{18}$ Flax N: The eye and learning disabilities. J. Learning Disabilities, 1973; 6: 328-32.

${ }^{19}$ Fowler MS and Stein JF: New evidence for 'Visual ambilaterality' in some dyslectics. Brit. orthopt. J. 1980; 37; 11-15.

${ }^{20}$ Goldberg HK: The ophthalmologist looks at the reading problem. Am. J. Ophthalmol. 1959; 47: 67-74.

${ }^{21}$ Goldberg HK: Vision, perception and related facts in dyslexia. I Keeney AH and Keeney VT: Dyslexia, diagnosis and treatment of reading disorders. CV Mosby Comp. St. Louis 1968, 90-109.

22 Goldberg HK and Arnott W: Ocular motility in learning disabilities. J. Learning Disabilities 1970; 3: 160-2.

${ }^{23}$ Griffin DC, Walton HN and Ives V: Saccades as related to reading disorders. J. Learning Disabilities 1974; 7: 310-16.

${ }^{24}$ Hallgren, B: Specific dyslexia (congenital wordblindness). A clinical and genetic study. Stockholm 1950.

${ }^{25}$ Helveston EM, Billips WC and Weber JC: Controlling eye-dominant hemisphere relationship as factor in reading ability. Am. J. Ophthalmol. 1970; 70: 96-100.

${ }^{26}$ Keeney AH: Ophthalmological aspects of dyslexia. Trans. Am. Acad. Ophthalmol. 1968; 72: 825-9.

${ }^{27}$ Keeney AH and Keeney VT: Dyslexia. Diagnosis and treatment of reading disorders. C. V. Mosby Co., St. Louis 1968.

${ }^{28} \mathrm{Keogh}$ BK: Optometric vision training programs for children with learning disabilities: Review of issues and research. J. Learning Disabilities, 1974; 7: 219-31.

${ }^{29}$ Norn MS, Rindziunski E and Skydsgaard H: Ophthalmologic and orthoptic examinations of dyslectics. Acta Ophthalmol. 1969; 47: 147-60.

${ }^{30}$ Orton ST: 'Word-blindness in school children'. Arch. Neurology and Psychiatry 1925; 14: 581615.

${ }^{31}$ Orton ST: Specific reading disability-Strephosymbolia. J. Amer. Med. Ass. 1928; 90: 1095-99.

32 Park GE: Reading difficulty (dyslexia) from the ophthalmic point of view. Am. J. Ophthalmol 1948; 31: 28-34.

${ }^{33}$ Rubino CA: and Minden HA: An analysis of eye- movements in children with reading disability. Cortex, 1973; 9: 217-20.

${ }^{34}$ Shearer RV: Eye findings in children with reading difficulties. J. Ped. Ophthal. 1966; 3: (4), 47-53.

35 Skydsgaard HB: Den konstitutionelle dysleksi. 'Ordblindhet'. En klinisk studie. Nyt Nordisk Forlag, (Kobenhavn) 1942).

${ }^{36}$ Stromberg EL: The relationship of measures of visual acuity and ametropia to reading speed. $J$. Appl. Psycho. 22: 1938; 70-8.

${ }^{37}$ Subirana A: The prognosis in aphasia in relation to cerebral dominance and handedness. Brian, 1958; 81: 415-25.

${ }^{38}$ Udnas I, Bruun S and Espeland A: Dyslexia og oyedominans. Foredrag Norsk Oftalm. Forening April 1977.

${ }^{39}$ Drake WE: Clinical and pathological findings in a child with a developmental learning disability. $J$. Learning Disabilities 1968; 1: 9-25.

${ }^{40}$ Duffy FH, Denckla MB: Bartels PH and Sandini G: Dyslexia. Regional differences in brain electrical activity by topographic mapping. Ann. Neurol. 1980; 7: 412-20.

${ }^{41}$ Duffy FH, Denckla MB, Bartels PH, Sandini G and Kiessling LS: Dyslexia: Automated diagnosis by computerised classification of brain electrical activity. Ann. Neurol. 1980; 7: 421-8.

42 Galaburda AM and Kemper TL: Cytoarchitectonic abnormalities in developmental dyslexia: A case study. Ann. Neurol. 1979; 6: 94-100.

${ }^{43}$ Hagberg B: Minimal brain dysfunction-Hvad innebaer det for barnets utveckling och anpassning? Lakartidningen, 1975; 72: 3296-300.

${ }^{44}$ Hier DB, LeMay M, Rosenberger PB and Perlo VP: Developmental dyslexia. Evidence for a subgroup with a reversal of cerebral asymmetry. Arch. Neurol. 1978; 35: 90-2.

${ }^{45}$ Leisman $\mathrm{G}$ and Schwartz J: Aetiological factors in dyslexia: 1 . Saccadic eye movement control. Perceptual and Motor Skills, 1978; 47: 403-7.

46 Pieston MS, Guthrie JT and Childs B: Visual evoked responses (VERs) in normal and disabled readers. Psychophysiology, 1974; 11: 452-7.

${ }^{47}$ Yeni-Komshian GH, Isenberg D and Goldberg H: Cerebral dominance and reading disability: Left visual field deficit in poor readers. Neuropsychologia 1975; 13: 83-94.

48 Newman SP, Wadsworth JF, Archer R and Hockley $\mathrm{R}$ : Ocular dominance, reading and spelling ability in school children. Br. J. Ophthalmol. 1985; 69: 228-32.

${ }^{49}$ Benton CD jr: Management of dyslexias associated with binocular control abnormalities. I Keeney, AH and Keeney, VT (eds.): Dyslexia. Diagnosis and treatment of reading disorders. C.V. Mosby Comp., St. Louis 1968, 143-153. 